\title{
Ciência sob embargo: um estudo de caso dos jornais O Globo e Folha
}

\section{Sofia Luisa Moutinho de Oliveira, Luisa Massarani e Luis Henrique Amorim}

\section{Resumo}

Este artigo analisa a influência do sistema de embargo praticado por periódicos científicos sobre a cobertura de ciência dos jornais diários brasileiros 0 Globo e Folha de S. Paulo. Esse sistema permite que jornalistas recebam informações privilegiadas sobre artigos científicos ainda não publicados com a expectativa de que preparem melhor sua cobertura.

\section{Palavras-chave}

Jornais diários. Mídia e Ciência. Sistema de embargo. Divulgação científica.

Sofia Moutinho | sofia.Imdo@gmail.com Bacharel em Jornalismo pela Universidade Federal do Rio de Janeiro (UFRJ), especialista em Divulgação da Ciência, da Saúde e da Tecnologia pelo Museu da Vida, Casa de 0swaldo Cruz (COC), Fundação Oswaldo Cruz (Fiocruz).

Luisa Massarani I luisa.massarani3@gmail.com Doutora em Gestão, Educação e Difusão em ciências pela Universidade Federal do Rio de Janeiro (UFRJ). Docente no Programa de PósGraduação em Comunicação, Cultura e Amazônia da Universidade Federal do Pará (UFPA), do Programa de Pós-Graduação em Ensino em Biociências e Saúde, do Programa de Pós-Graduação em História da Ciência e da Saúde e no Curso de Especialização em Divulgação da Ciência, da Tecnologia e da Saúde (lato sensu), todos da Fundação Oswaldo Cruz (Fiocruz). É Honorary Fellow do Department of Science and Technology Studies da University College London (UCL), Reino Unido.

\section{Luís Amorim I lha@fiocruz.br}

Mestre em Ensino em Biociências e Saúde no Instituto Oswaldo Cruz, Fundação Oswaldo Cruz (Fiocruz), na linha de pesquisa Ciência e Mídia. Coordenador do Núcleo de Estudos da Divulgação Científica/ Museu da Vida/Casa de Oswaldo Cruz/Fiocruz.

\section{Introdução}

Todos os dias leitores de jornais são

bombardeados com notícias sobre os avanços da ciência. Mas muitas dessas notícias, na verdade, já eram do conhecimento de jornalistas alguns dias antes do resto do mundo e de grande parte da comunidade científica, graças ao chamado sistema de embargo. Trata-se de um "acordo de cavalheiros" em que periódicos científicos especializados enviam para jornalistas do mundo inteiro informações privilegiadas relacionadas a artigos científicos ainda não publicados (releases sobre as pesquisas, imagens e materiais multimídias, contato dos cientistas e cópia do próprio artigo científico). Em troca, os jornalistas - que precisam se cadastrar previamente e ser aceitos para fazer parte deste acordo comprometem-se a só divulgar as informações após determinada data e hora e citar o nome do periódico científico em suas notícias.

0 sistema de embargo não é exclusividade do jornalismo científico. Na cobertura de política e de economia, por exemplo, é comum o jornalista 
receber informações privilegiadas de fonte oficial antecipadamente. No entanto, em geral, nesses casos não há por trás um sistema tão complexo e estruturado quanto o dos periódicos científicos. Comandado principalmente por publicações dos Estados Unidos e da Inglaterra, esse sistema encontra seus maiores representantes em Science e Nature. As duas revistas estão entre as de maior impacto no campo acadêmico e mantêm na internet canais diretos com os jornalistas mediante registro gratuito.

A história do embargo dos periódicos remonta ao início do século XX e é ilustrativa de como foi se estabelecendo a relação de interesses entre ciência e jornalismo, dois importantes pilares da sociedade contemporânea. Segundo Kiernan (2006), uma das primeiras formas de embargo foi criada em 1921 nos Estados Unidos. Era a Science Service, uma agência de notícias especializada, sem fins lucrativos, que visava promover a popularizaçãa da ciência distribuindo material sob embargo para os jornais associados. Segundo o criador da agência, Edwin E. Slosson, esse sistema foi criado para prevenir os erros de interpretação e os mal-entendidos do anúncio de uma descoberta científica (KIERNAN, 2006). Esse argumento ainda hoje é usado como justificativa pelos periódicos que adotam o sistema de embargo. 0s editores dessas publicações defendem que fornecer mais tempo para a apuração jornalística que 0 usual permite uma cobertura de mais qualidade e com menos erros.
0 sistema de embargo traz benefícios para muitos dos atores envolvidos. Ele provê visibilidade aos periódicos científicos em meios de comunicação de todo o mundo e, em consequência, visibilidade aos pesquisadores que assinam os artigos científicos. Além disso, o sistema garante para os jornalistas pautas semanais sobre pesquisas que já passaram por um sistema de avaliação por pares, seguindo os procedimentos usuais de uma revista científica. Embora tal sistema não seja infalível, garante, pelo menos em certa medida, respaldo ao material quanto à sua precisão e relevância científica. No entanto, essa política é questionável tanto do ponto de vista do jornalismo quando dos leitores. A retenção de informação do público, a homogeneização de pautas e a publicidade gratuita para os periódicos são apenas algumas das implicações do sistema que suscitam reflexão. Para analisar como esse sistema vem sendo utilizado por jornalistas no Brasil e a influência que ele tem - ou não - sobre a cobertura de ciência, dedicamo-nos ao estudo de caso de notícias publicadas sob o embargo das revistas científicas Science e Nature nos jornais de repercussão nacional $O$ Globo e Folha de S. Paulo.

\section{Metodologia}

\section{Selecionamos $O$ Globo e Folha de S. Paulo} por causa de seu status no país e por serem publicados no Rio de Janeiro e São Paulo, polos econômicos e culturais. Os jornais se inserem nos chamados "jornais de elite", destinados às classes média e alta, sendo também publicações 
de referência para formuladores de políticas.

A Folha tem uma circulação média de 297.650 exemplares de segunda-feira a domingo e $O$ Globo, de 277.876. ${ }^{1}$

Para este estudo foram analisadas todas as notícias publicadas nas seções de ciência de O Globo e Folha por cinco meses, de março de 2012 a julho de 2012. Textos de ciência e tecnologia são publicados com frequência em outras editorias (MASSARANI et al., 2008), mas optamos por analisar apenas os publicados nas seções específicas de ciência por considerarmos que é mais provável encontrar matérias produzidas com 0 sistema de embargo nesses espaços e porque esse recorte favorece um melhor entendimento sobre a concepção dessas editorias, nas quais atuam jornalistas especializados na cobertura de temas de ciência.

Do universo geral de notícias de ciência publicadas no período analisado, identificamos aquelas que mencionaram periódicos científicos. Os títulos desses periódicos foram listados e quantificamos a frequência que cada um deles foi citado por ambos os veículos. Desse conjunto de notícias, foram identificadas aquelas produzidas a partir do sistema de embargo. Para isso, foi feita uma pesquisa para verificar quais títulos possuem o sistema. A partir daí, selecionaramse para estudo apenas as matérias sobre artigos científicos publicados na Science e na Nature.
A partir desse corpus, foram feitas análises

quantitativas e qualitativas. A análise quantitativa baseou-se na análise de conteúdo que, de acordo com Bardin (1979, p. 31), "é um conjunto de técnicas de análise das comunicações". Assim, procuramos quantificar alguns elementos que pudessem revelar características gerais da apuração das matérias. Primeiramente, foram identificadas e contabilizadas as notícias que traziam declarações em seu corpo. Essas declarações foram registradas segundo sua origem (se foram conseguidas por meio de entrevista ou retiradas dos releases) e autoria (se eram dos autores dos artigos, de cientistas não envolvidos com a pesquisa, de leigos ou de outros setores sociais).

Já a análise qualitativa baseou-se em proposta delineada por Fahnestock (1993) sobre o processo de transformação que os textos científicos passam para se tornarem jornalísticos. A autora distingue os textos científicos dos de divulgação científica pelas características aristotélicas do discurso. No modelo aristotélico, a retórica divide-se em três gêneros de discurso: judiciário, que discute sobre a natureza e causa de eventos passados e usa estratégias de convencimento; deliberativo, que estabelece melhor caminho para ações futuras, e epidítica, que diz respeito a julgamentos atuais e avalia se algo merece elogios ou censuras.

Para Fahnestock (1993), os artigos científicos como é o caso dos textos dos periódicos científicos de Science e Nature -, estão na categoria de 
judiciários. Esses textos não tentam convencer 0 leitor sobre a relevância de seu enunciado, pois sua significação é, na maioria das vezes, subentendida - não descrita no discurso, mas perceptível pelo seu contexto. Já os textos de divulgação científica como é o caso dos textos jornalísticos desse estudo - seriam epidíticos, com a intenção de celebrar e não validar. Ao contrário dos textos científicos, não podem pressupor que o leitor reconheça a importância do enunciado, por isso o valor do trabalho divulgado é reforçado. Segundo Fahnestock (1993), no jornalismo científico, o trabalho de retórica epidítica ajusta a informação para os valores e suposições do leitor. Embora os textos jornalísticos não possam todos ser homogeneizados e classificados como de celebração, a proposta de Fahnestock pode ser útil para esse estudo. Pela comparação de artigos publicados na Science com as notícias que saíram sobre eles, a autora mostrou que, na mudança do gênero judiciário (da ciência) para o epidítico (da divulgação), há mudanças na informação e que, portanto, o trabalho jornalístico envolve um processo de acomodação que passa pela produção de outro discurso. Seguindo a linha de Fahnestock (1993), Massarani e Moreira (2002) e Massarani e colaboradores (2005) propuseram uma metodologia para analisar esse processo de transformação em jornais da América Latina. Este estudo se insere nesta proposta, que vem sendo realizada no âmbito do Núcleo de Estudos da Divulgação Científica do Museu da Vida.

Para este artigo, selecionamos as notícias sob embargo publicadas nos dois jornais que se referiam a uma mesma pesquisa e as comparamos entre si e com os releases e artigos oferecidos pelos periódicos na tentativa de ver como se dá a acomodação do discurso científico no discurso jornalístico. Para isso, identificamos as similaridades e as diferenças entre 0 material embargado e as notícias tanto em forma quanto em conteúdo. Foram considerados: (1) os "ganchos" jornalísticos; (2) as informações que apareceram, desapareceram e são reorganizadas e (3) a presença ou ausência de incertezas e controvérsias em relação às pesquisas relatadas. 0 acesso ao material embargado (artigos e releases) se deu por meio de cadastro nos sistema de embargo de Science e Nature.

\section{Resultados}

\subsection{Análise quantitativa}

Registramos um total de 547 notícias de ciência no período analisado (384 da Folha e 163 de 0 Globo). Uma explicação para a maior quantidade de notícias da Folha poderia ser o fato desse jornal ter uma seção de ciência diária enquanto $O$ Globo publica sua seção de ciência apenas de terças às sextas-feiras.

Desse universo, identificamos 85 notícias (53 na Folha e 32 em 0 Globo) que citaram 28 periódicos (todos internacionais) como fonte para suas pautas, dos quais 22 têm sistema de embargo. Os periódicos mais mencionados foram Nature, em 20 matérias, e Science, em 19. Juntos, os dois respondem por $45,9 \%$ do 
total de notícias embargadas publicadas nos dois jornais no período analisado: 13 de 0 Globo e 26 da Folha.

Verificamos que a maior parte dos textos, $71,7 \%$ (28 de 39), apresenta a voz de pelo menos um cientista ligado à pesquisa anunciada, e nove textos (23,0\% do total) trazem declarações de cientistas independentes. Dentro desse universo, quatro textos apresentam tanto declarações de cientistas independentes quanto de cientistas ligados ao estudo reportado. Outros quatro textos exibem somente declarações de cientistas independentes. Também verificamos que 17,9\% dos textos (sete de 39) não apresentam quaisquer declarações, seja de cientistas envolvidos ou não na pesquisa em questão, seja de qualquer outro ator social. Desse modo, a distribuição de notícias por autor de declarações fica como no gráfico abaixo (Figura 1).

Observamos que 19 das 24 notícias $(79,1 \%)$ que apresentam declarações somente de cientistas envolvidos na pesquisa exibem apenas um entrevistado, geralmente 0 autor principal do estudo. A quantidade máxima de entrevistados observada nos quatro textos restantes foi de dois. 0 padrão se repete no pequeno grupo de notícias que apresentam declarações de cientistas não ligados à pesquisa reportada. As quatro notícias que trazem somente a voz de cientistas independentes apresentam apenas uma fonte de declaração. As quatro notícias que mesclam declarações de cientistas independentes com as de cientistas ligados à pesquisa reportada também apresentam 0 máximo de duas fontes citadas.

A análise sugere que, de maneira geral, as notícias sobre ciência dos veículos analisados dão prioridade para a voz dos pesquisadores diretamente envolvidos com as pesquisas reportadas. Mas um exame mais detalhado da origem dessas vozes mostra que nem todas as declarações exibidas nas matérias foram conseguidas pelo jornalista por meio de

Figura 1: 0 gráfico mostra os números absolutos e a porcentagem de notícias analisadas conforme vozes presentes

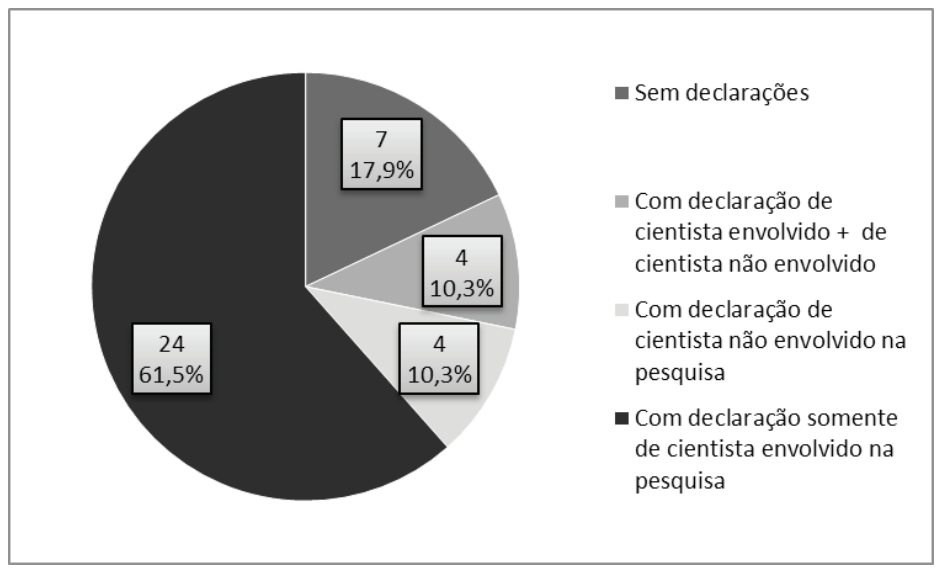


entrevista. Treze das 24 matérias que trazem somente declarações de autores das pesquisas foram feitas exclusivamente com base em entrevista (cinco de $O$ Globo e seis da Folha) e 11 apresentam declarações conseguidas em releases disponibilizados pelos periódicos. As notícias com declarações de releases representam 28,2\% do total de notícias analisadas e $45,8 \%$ das notícias que apresentam somente declarações de cientistas envolvidos nas pesquisas.

Entre essas notícias, sete (três de $O$ Globo e quatro da Folha) usam as declarações retiradas dos releases como única fonte de declarações. Das quatro restantes, três, de $O$ Globo, mesclam as declarações de assessoria com declarações de cientistas conseguidas por meio de entrevista e uma, da Folha, traz trechos do artigo reportado entre aspas. A Folha foi 0 veículo que mais adotou o recurso de citações ao artigo científico. Foram identificadas ainda três notícias que apresentaram somente essas citações ao artigo sem ouvir ninguém, sendo duas da Folha. Vale ressaltar também que em apenas uma das 11 notícias que usaram declarações retiradas de release foi dado 0 devido crédito da origem dessa fala.

Os resultados sugerem que o release é uma fonte importante na produção das notícias. Além de muitos textos exibirem declarações retiradas de material de assessoria de imprensa, verificamos também influência do release na escolha das fontes entrevistadas. Das 13 notícias em que foram ouvidos pesquisadores ligados aos estudos reportados, nove, 0 equivalente a $69,2 \%$, apresentam apenas fontes indicadas e citadas nos releases. Das quatro notícias que exibem declarações de pesquisadores não sugeridos pelo release como fonte, duas exibem a voz de cientistas brasileiros envolvidos na pesquisa relatada.

As notícias que trazem declarações de cientistas independentes são escassas (apenas oito em 39). Além disso, algumas delas possuem aspas de origem indireta: seis dessas oito notícias (cinco da Folha e uma de $O$ Globo) apresentam declarações de pesquisadores estrangeiros retiradas de comentários ao artigo científico publicados na Science e na Nature nas seções destinadas a esse fim - News and Analysis e Perspective, na primeira revista, e News and Views, na segunda. Nesses espaços, pesquisadores convidados discutem a validade e as implicações científicas de determinados artigos. Assim, identificamos, no total, 21 notícias que apresentaram declarações obtidas por entrevista, 11 com declarações retiradas de releases, seis com citações retiradas de comentários publicados nos periódicos e sete com trechos do artigo científico (Tabela 1):

Nossa análise indicou ainda a existência de uma prática recorrente no período analisado: a cópia de trechos e frases do release. Foram identificadas cinco matérias com parágrafos inteiros retirados do release, com destaque para duas de $O$ Globo. Uma delas, 
Tabela 1: Origem das declarações nas notícias analisadas (números absolutos)

\begin{tabular}{|l|c|c|c|}
\hline \multicolumn{1}{|c|}{ Notícias com: } & Folha & 0 Globo & TOTAL: \\
\hline Citação de artigo científico & 6 & 1 & 7 \\
\hline Citação de comentários publicados nos periódicos & 5 & 1 & 6 \\
\hline Declarações retiradas de releases & 5 & 6 & 11 \\
\hline Declarações conseguidas por entrevistas & 13 & 8 & 21 \\
\hline
\end{tabular}

"Rato paralítico volta a andar" (01/06/2012), ${ }^{2}$ sobre um experimento em que um rato com rompimento da medula espinhal teve sua locomoção restaurada com ajuda de um andador, é uma tradução integral do release oferecido pela Science. Outra, "0 gene da diversidade" (04/05/2012), ${ }^{3}$ apresenta diversos trechos traduzidos do release oferecido pela Science reordenados de modo a compor uma notícia muito semelhante ao material fornecido por assessoria.

\subsection{Análise qualitativa}

Como mencionado anteriormente, a análise qualitativa incidiu sobre as notícias coincidentes nos dois jornais, ou seja, os casos em que ambos os jornais cobriram um mesmo artigo científico. Foram cinco essas ocorrências com os seguintes temas: a análise do DNA dos gorilas $(\text { Nature })^{4}$, a descoberta de um dinossauro chinês com penas (Nature) ${ }^{5}$, a descoberta de uma construção maia e um calendário do mesmo povo (Science) $)^{6}$, um experimento que implantou um chip no cérebro de pessoas com paralisia para que elas movimentassem um braço robótico (Nature $)^{7}$ e a descoberta da cerâmica mais antiga já encontrada (Science). ${ }^{8}$ Aqui analisamos alguns aspectos desses textos.

\subsubsection{0s "ganchos" jornalísticos}

0 "gancho", no jornalismo, se refere à maneira de contextualizar a matéria e ligar 0 assunto da pauta à realidade do leitor, seja pela atualidade, pela relevância, pelo ineditismo ou outros motivos que sejam pretextos para a produção da notícia. A comparação entre os "ganchos" adotados pelas matérias publicadas em $O$ Globo e Folha com o "gancho" dos releases mostra que esse material tem forte influência sobre a composição dos textos jornalísticos. 
Nas notícias "Tiranossauro chinês era coberto de penas" (Folha, 05/04/2012) e "Um tirano felpudo" ( $O$ Globo, 05/04/2012), sobre a descoberta do dinossauro coberto de penas, ambos os jornais usaram um tom de humor na abertura da notícia que não estava presente nem no release nem no artigo científico:

Milhões de anos antes de o Tyranosaurus rex sacudir a atual América do Norte, seu antepassado aterrorizou 0 outro lado do globo. 0 predador chinês, porém, tinha suas particularidades. Era um pouco mais baixo (nove metros, três a menos que 0 rival famoso), mais leve ( 1,4 tonelada -0 Rex chegava a cinco) e bem mais fofo. Literalmente. Seu nome já denuncia esta característica. Paleontólogos chineses e canadenses, responsáveis por sua descoberta, 0 batizaram de Yutyrannus huali - uma mistura de latim e mandarim que, em português literal, resulta em 'belo tirano de penas' (O Globo, 05/04/2012).

Tanto a matéria de $O$ Globo quanto a da Folha citam o T. rex como elemento de comparação, sugestão que é dada pelo release. Provavelmente, a escolha dos jornalistas se deu pela popularidade desse dinossauro já consagrado no imaginário do leitor por meio de filmes e desenhos animados. Como lembra Traquina (2005), o uso de um elemento já conhecido pelo público é uma estratégia para chamar a atenção do leitor e aproximá-lo do tema, não é à toa que ambos os jornais citaram o T. rex nos primeiros parágrafos.

Apesar de citar o T. rex, a Folha primeiramente compara o novo dinossauro a um pintinho, aproveitando-se da analogia feita na declaração do líder da pesquisa no release, onde diz que "Ela [a penugem] era mais semelhante à difusa e curta de um pintinho moderno do que as penas duras de um pássaro adulto." 9

Nas notícias sobre a cerâmica mais antiga do mundo, os jornais adotaram aberturas muito semelhantes à proposta pelo periódico com um lead comportado que teve como gancho o ineditismo da peça encontrada:

A cerâmica é bem mais antiga do que se imaginava: fragmentos com cerca de 20 mil anos de idade foram achados na caverna de Xianrendong, na China, recuando em até 3.000 anos 0 uso conhecido desses artefatos (Folha, 29/06/2012).

O Globo segue a mesma linha e abre a notícia da seguinte maneira:

Fragmentos de cerâmica encontrados em uma caverna no Sul da China teriam 20 mil anos, sendo os mais antigos conhecidos no mundo, segundo arqueólogos envolvidos na descoberta (0 Globo, 29/06/2012).

Já os textos "Calendário celeste dos maias tem 1.200 anos" (Folha, 11/05/2012) e "Muito além de 2012" (O Globo,11/05/2012) são as notícias sobre um mesmo artigo científico que mais diferem entre si. 0 artigo publicado na Science descreve 0 achado das tabelas astronômicas maias mais antigas até então conhecidas. As tabelas, espécies de cálculos astronômicos usados para confeccionar calendários, foram encontradas em uma estrutura 
que os pesquisadores acreditam se tratar do antigo quarto de um escriba. 0 artigo publicado na Science descreve em detalhes as tabelas e também outras pinturas achadas nas paredes do cômodo escavado. Segundo 0 artigo, a descoberta é importante por ter o potencial "[...] de lançar luz nos estudos sobre os livros astronômicos mais recentes" da cultura maia. 0 release também dá destaque à descoberta do cômodo e das tabelas.

Como vemos na linha fina, a Folha segue a linha do material fornecido e usa como gancho a descoberta em si, ressaltando a sua relevância para 0 estudo da cultura maia: "Pesquisa revelou mais antigo caso de tabelas astronômicas desse povo. Números registram ciclos da Lua, de Marte, de Vênus e de Mercúrio; um dos objetivos era tentar prever eclipses" (Folha, 11/05/2012).

No release, há uma citação do autor principal da pesquisa, que usa uma metáfora para explicar sua descoberta: "É como um episódio do programa de TV ‘Big Bang Theory’, eles pintavam na parede problemas matemáticos nerds. Parece que eles usavam a parede como um quadronegro", diz o release $e^{10} 0$ texto Folha aproveita essa ideia em sua abertura:

É como se o quadro-negro de uma aula de astronomia que aconteceu há mais de mil anos tivesse sido encontrado em meio à selva da
Guatemala. 0s números anotados por um escriba maia estão borrados, mas ainda visíveis" (Folha, 11/05/2012).

Já a matéria de $O$ Globo apresenta um gancho diferente: relaciona a pesquisa à crença de que os maias teriam previsto o fim do mundo para dezembro de 2012. A ideia que rondava 0 imaginário popular à época da publicação não foi mencionada pelo artigo da Science e não tinha nenhuma relação direta com a descoberta, mas foi usada como chamariz no release também. A linha fina do release diz: "Números pintados refletem calendário que vai muito além de 2012." 0 título, a linha fina e o lead da matéria de $O$ Globo repetem a ideia:

\section{Muito além de 2012}

Escavações revelam mural maia com calendários que avançam quase 7 mil anos

Apesar das teorias apocalípticas, 2012 não é nem de longe 0 último ano previsto no calendário da civilização maia. Escavações nas ruínas de Xultún, megacidade maia no nordeste da Guatemala, revelaram um mural com tabelas astronômicas que avançam quase 7 mil anos no futuro. (0 Globo, 11/05/2012)

\subsubsection{As vozes envolvidas}

Como apontado pela análise quantitativa, as notícias coincidentes também apresentam como principais fontes os pesquisadores envolvidos diretamente nas pesquisas anunciadas. Todas as

"It's like an episode of TV's 'Big Bang Theory,' a geek math problem and they're painting it on the wall. They seem to be using it like a blackboard." 
dez notícias sobre os cinco estudos publicadas pelos dois jornais apresentam pelo menos uma declaração de um autor dos artigos divulgados.

As declarações dos autores, no entanto, como foi visto na análise quantitativa, nem sempre foram originadas de entrevista feita pelo jornalista brasileiro, mas, sim, retiradas de releases enviados pelos periódicos. Isso aconteceu em três matérias, duas da Folha e uma de $O$ Globo.

A notícia "Dinossauro carnívoro chinês parecido com T. rex tinha corpo revestido de penas" ( $O$ Globo, 05/04/2012) é um exemplo de texto que traz declarações retiradas do release (Quadro 1):

Já a matéria "DNA reforça elo entre humanos e gorilas" (03/03/2012), publicada na Folha usa a estratégia - identificada na análise quantitativa - de introduzir uma declaração de um pesquisador não ligado à pesquisa retirada de uma seção de comentários do periódico que publicou o artigo:

Em um artigo crítico que acompanha a pesquisa, publicado na revista "Nature", Richard Gibbs e Jeffrey Rogers, do Centro de Sequenciamento do Genoma Humano da Faculdade de Medicina de Baylor, em Houston, destacam os resultados. "Esses novos dados sobre os gorilas sugerem que uma grande porção do genoma humano estava sob pressão da seleção positiva [sendo favorecida pela seleção natural] durante 0 período de isolamento inicial dos nossos parentes próximos", avaliam (Folha, 03/03/2012).

Quatro das notícias coincidentes incluíram declarações que não foram obtidas por contato direto entre os cientistas e os jornalista brasileiro. Um exemplo é "Um gole para história" (O Globo, 29/06/2012), sobre o braço robótico comandado por pensamento. O Globo não ouviu nem os autores nem outros pesquisadores não relacionados ao estudo. A matéria se destaca pelo tamanho (é a maior dentre as analisadas, com cerca de seis mil caracteres e o dobro do tamanho das demais) e traz apenas declarações retiradas de releases. São exibidas na matéria declarações de três fontes: 0 autor principal da pesquisa, o coautor e uma fonte leiga. Science deu grande destaque para esse estudo e colocou à disposição dos jornalistas cadastrados no sistema de embargo três releases

Quadro 1: Comparação entre release e notícia

\begin{tabular}{|l|l|}
\hline \multicolumn{1}{|c|}{ Release da Nature } & \multicolumn{1}{|c|}{ Notícia de $\mathbf{0}$ Globo } \\
\hline $\begin{array}{l}\text { "Yutyrannus dramatically increases the size range } \\
\text { of dinosaurs for which we have definite evidence of } \\
\text { feathers," Professor Xu said. "It's possible that feathers } \\
\begin{array}{l}\text { were much more widespread, at least among the } \\
\text { meat-eating dinosaurs, than most scientists would have } \\
\text { guessed even a few years ago." }\end{array}\end{array}$ & $\begin{array}{l}\text { [...]-0 yutirano aumenta drasticamente a escala } \\
\text { - revelou o professor Xu Xing, do Instituto de } \\
\text { Paleontologia de Vertebrados de Pequim. - É possível } \\
\text { que as penas tenham sido muito mais disseminadas, } \\
\text { ao menos entre os carnívoros. }\end{array}$ \\
\hline
\end{tabular}


diferentes sobre 0 experimento relatado. 0 Globo aproveitou esse material e usou declarações retiradas de todos os releases para compor a matéria, o que sugere que 0 material de assessoria recebeu bastante atenção durante a apuração da notícia.

Também observamos que nenhum dos textos apresentou pareceres e comentários de pesquisadores independentes conseguidos em entrevista. Fora os casos em que foram introduzidas declarações retiradas de comentários sobre os estudos publicados pelos próprios periódicos, não foi ouvido ninguém além dos autores dos estudos relatados.

\subsubsection{Informações que aparecem, desaparecem e são reorganizadas}

Ao compararmos as notícias de nosso corpus com os releases providos pelos periódicos e os respectivos artigos científicos, percebemos que existem informações que são conservadas no processo de acomodação do texto científico e de assessoria para o jornalístico, bem como informações que são descartadas e outras que são adicionadas nas notícias. A análise dessas informações fornece material para reflexão sobre a qualidade e 0 aprofundamento da apuração e construção das notícias feitas sob embargo.

Observamos que muitas das notícias analisadas suprimem a técnica e a metodologia utilizadas pelas pesquisas relatadas, informações que estão sempre presentes nos artigos científicos e por vezes nos releases também. A ausência da técnica utilizada foi identificada nas notícias sobre as três pesquisas que tratam de descobertas paleoarqueológicas - a descoberta do fóssil de um dinossauro com penas na China, a descoberta de tabelas astronômicas maias e a descoberta das cerâmicas mais antigas do mundo.

0s textos "Cientistas acham cerâmica mais antiga do mundo na China" (Folha, 29/6/2012) e "Cerâmica de 20 mil anos achada na China" $(O$ Globo, 29/06/2012) relatam a descoberta dos mais antigos fragmentos de cerâmica encontrados até o momento, mas nenhum dos dois explica como a datação foi feita. As conclusões do estudo são apresentadas sem as evidências científicas que as tornaram possíveis. 0 resumo da Science que acompanha 0 artigo traz essa informação e 0 artigo científico também. Ambos explicam que a estimativa da idade foi conseguida de maneira indireta, por meio da datação de radiocarbono das camadas de detritos em que 0 artefato foi encontrado.

As outras notícias coincidentes e seus respectivos releases apresentam mais informações sobre a metodologia, ainda que de maneira superficial. Interessante destacar que essas notícias são sobre estudos de áreas biológicas. A matéria "DNA reforça elo entre humanos e gorilas", da Folha, explica como os resultados do estudo foram conseguidos, a partir da análise comparativa do genoma de gorilas, humanos, chimpanzés e orangotangos. 0 texto ainda conta que 0 sequenciamento genético do gorila, 0 
primeiro a ser feito, teve como base o DNA de uma gorila chamada Kamilah:

Para chegar a esse resultado, um força-tarefa de 71 pesquisadores de várias partes do mundo esmiuçou o genoma de Kamilah, uma gorila-comum-ocidental (Gorilla gorilla gorilla) de 31 anos, e comparou os resultados com os genes dos outros três grandes primatas: humanos, chimpanzés e orangotangos (Folha, 08/03/2012).

A informação sobre a gorila está destacada no terceiro parágrafo do release, que traz ainda mais detalhes sobre a gorila, que tem toda a sua família próxima nomeada no texto da assessoria. A gorila Kamilah também é citada no artigo científico, contudo sem o mesmo destaque. 0 texto científico não apresenta informações sobre a família ou moradia do animal e cita ainda outros três gorilas usados na pesquisa e não referidos no release.

Ao contar a mesma notícia, sobre o sequenciamento genético do gorila, $O$ Globo não cita diretamente a metodologia do estudo. A notícia foca 0 sequenciamento do genoma do gorila, destaca as semelhanças e diferenças do DNA do animal em relação ao dos humanos, dos chimpanzés e dos orangotangos, mas não diz explicitamente como essa comparação foi feita. Não há, como no texto da Folha e no release, um parágrafo dedicado à metodologia.

Nas notícias "Um gole para história" e "Mulher mexe braço-robô com a mente", percebemos a influência dos releases no direcionamento de informações. Ambas as notícias só mencionam as instituições de pesquisa participantes citadas nos releases. Outras instituições que também realizaram a pesquisa e estão referenciadas apenas no artigo, não são citadas. Também verificamos que algumas informações cruciais presentes nos artigos científicos ficaram de fora ou foram mal colocadas em algumas matérias. A notícia sobre a descoberta do dinossauro com penas de $O$ Globo, por exemplo, não informa ao leitor a idade estimada do fóssil. 0 texto apenas cita que o dinossauro encontrado teria vivido 55 milhões de anos antes do T. rex, sem mencionar também quando esse tiranossauro viveu. 0 release também não informa a idade do fóssil, citando apenas que ele foi encontrado em camadas do Cretáceo.

\subsubsection{Controvérsias e incertezas}

Tentamos identificar nas notícias coincidentes a presença de controvérsias e incertezas científicas e observar como elas foram apresentadas pelos jornalistas. Quando estas não estavam presentes, procuramos ver se haveria a possibilidade de estarem.

As notícias coincidentes aqui analisadas não necessariamente apresentam temas notoriamente controversos ou polêmicos. No entanto, alguns dos artigos deixam questões em aberto e apontam para a possibilidade de outras versões e explicações para suas conclusões. Este é o caso do artigo da Nature sobre 0 dinossauro com penas. 0 trabalho científico parte da descoberta de fósseis de esqueletos 
incompletos de dinossauros que apresentam fragmentos esparsos de penas e conclui que os animais teriam o corpo inteiro coberto. A notícia publicada na Folha chega a mencionar incertezas científicas, mas a de $O$ Globo sobre 0 assunto não deixa espaço para questionamentos sobre essa conclusão e afirma já na abertura que os animais eram cobertos de penas. 0 artigo científico, no entanto, é mais cauteloso ao fazer afirmações e apenas indica essa explicação como uma das possíveis. 0 texto científico diz: "Deve ser notado que a plumagem está preservada apenas parcialmente nos três espécimes conhecidos do $Y$ huali e a possibilidade de que as penas tenham tido distribuição restrita no corpo não pode ser completamente excluída" (Nature, 05/04/2012).

Dentre as notícias coincidentes, a que tem potencial para levantar mais controvérsias é sobre 0 experimento com 0 braço robótico movido pela mente. Por ser um procedimento invasivo, que implanta eletrodos no cérebro dos pacientes e por ter a chance de se tornar uma forma de intervenção médica, 0 experimento poderia suscitar questionamentos éticos. 0 fato de se tratar de uma tecnologia de interface cérebro-máquina, que poderia ser usada fora do campo médico, também abre espaço para discussões filosóficas acerca do que é o ser humano e máquina e dos aspectos negativos e positivos da tecnologia na vida humana. Esses questionamentos, no entanto, não foram apresentados no artigo científico, nem nos releases - que têm por objetivo enaltecer a pesquisa -, nem nas notícias, que não apresentam outras declarações além das dos pesquisadores envolvidos.

\section{Discussão}

Neste artigo, fizemos um estudo exploratório com o objetivo de entender em que medida 0 sistema de embargo praticado pelas revistas científica Science e Nature influencia as notícias de ciência em dois importantes jornais brasileiros. Comparamos os materiais sob embargo com as notícias jornalísticas e percebemos que os primeiros têm grande influência na forma e no conteúdo dos últimos. De modo geral, identificamos que as notícias produzidas sob embargo utilizam fontes indicadas pelos periódicos, na maioria das vezes o próprio autor do estudo científico relatado, e com frequência não apresentam a visão de cientistas independentes. Nossos dados sugerem que 0 período adicional de uma semana de vantagem concedido pelos periódicos aos jornalistas que participam do sistema de embargo não foi usada para entrevistar mais pesquisadores, ouvir mais fontes ou buscar informações diferenciadas. Como nosso estudo se restringiu a um período de cinco meses e incidiu em apenas dois jornais, os resultados não podem ser generalizados. Mas não deixam de suscitar questões importantes. A primeira delas é a possibilidade de que o próprio sistema de embargo dificulte a apuração das notícias, pois os cientistas que não participam das pesquisas relatadas não têm acesso antecipado aos artigos e por isso ficam limitados para comentá-los. 
Ainda que justificável pela lógica de produção corrida de um jornal diário, a escassez de fontes e a prática de ouvir apenas os autores da pesquisa noticiada não deixa de ser questionável na medida em que gera uma cobertura consensual da ciência, sem contrapontos e orientada pelos interesses dos autores dessas pesquisas e dos periódicos que as publicam. Uma cobertura jornalística que destaque os aspectos positivos da ciência é de interesse dos cientistas, bem como dos periódicos que mantém sistemas de embargo e das instituições de pesquisa que provem releases para esse sistema. Como lembra Nelkin (1995), cientistas - e nesse caso periódicos também - têm necessidade não só em manter sua legitimidade, como seus interesses econômicos, que podem ser garantidos com a promoção de suas pesquisas. No caso do sistema de embargo, existe 0 aval da revisão por pares que supostamente garante a qualidade das pesquisas, mas este sistema não é infalível.

A ausência de outras perspectivas e de uma discussão sobre controvérsias e incertezas científicas nas pesquisas relatadas pode provocar no leitor expectativas que nem sempre serão atendidas - esta situação pode ser especialmente grave quando se trata de temas que influem diretamente na vida do público, como a medicina.

Vale destacar também que foi recorrente nas notícias analisadas o uso de trechos e declarações retiradas dos releases oferecidos pelos periódicos sem a devida citação de sua origem. Fora a questão do direito autoral, esse quadro preocupa porque demonstra 0 alto nível de influência do discurso dos periódicos que capitaneiam o sistema de embargo sobre a produção das notícias.

Verificamos ainda que as notícias sob embargo de Science e Nature publicadas em 0 Globo e Folha são de cobertura factual e datada, não se desdobram em discussões amplas nem apresentam diferentes facetas do tema abordado. A maioria das notícias se justifica pela atualidade da descoberta relatada, por ser a mais última novidade na área. Foram frequentes os textos anunciando "o mais antigo", "0 maior", "o mais avançado até o momento". Esse tratamento contribui para uma visão de ciência distorcida em que ficam ocultos os longos processos por trás da construção do conhecimento. Para o leitor, fica a impressão de urgência e produtividade instantânea.

Essa aparência de urgência é inclusive uma crítica comum ao sistema de embargo, apontada por Kiernan (2006) ao descrever uma das consequências do embargo: 0 "modelo do grande artigo da semana". Segundo o autor, o sistema prioriza o destaque na mídia dos últimos "grandes acontecimentos" a despeito de sua real relevância. 0 ex-editor da Scientific American, Jonh Rennie (2011), também comenta essa situação e afirma que o sistema de embargo contribui para um "jornalismo de bando" (do inglês, pack 
journalism $),{ }^{12}$ caracterizado pelo domínio de textos uniformes produzidos por jornalistas que já sabem que seus concorrentes também estão trabalhando nas mesmas notícias.

Embora a uniformização de pautas seja destacada como um dos perigos do sistema de embargo, não identificamos esse cenário no presente estudo. As notícias de temas coincidentes foram poucas, apenas cinco em meio a 39 textos de embargo. 0 vasto cardápio de pautas que os periódicos oferecem aos jornalistas e 0 amplo espectro de periódicos monitorados pode explicar a pouca repetição de pautas.

Ainda assim é importante destacar que embora não tenha havido homogeneização de pautas nos jornais analisados, a fidelização de procura por pautas nesses periódicos configura um olhar parcial e geograficamente localizado sobre a ciência mundial. Os periódicos utilizados como fonte de notícia são em sua maioria, a exemplo de Science e Nature, dos Estados Unidos e Inglaterra e trazem em peso pesquisas desses países que não necessariamente atendem às nossas demandas sociais e econômicas.

0s dados expostos nesse trabalho parecem indicar que 0 sistema de embargo beneficia os periódicos e os cientistas que publicam nessas revistas, pois ambos obtêm visibilidade na mídia. Mas, na prática, a cobertura de ciência e o público são prejudicados, bem como outros cientistas cujos estudos não foram divulgados nestes periódicos. Isto é particularmente relevante quando lembramos que todos os periódicos citados eram estrangeiros. Visto 0 apresentado, consideramos fundamental uma discussão mais aprofundada sobre 0 sistema embargo e as notícias de ciência, em particular no contexto brasileiro.

\section{Referências}

AMORIM, L. Jornalismo científico na América Latina: um estudo de caso de sete jornais da região. Rio de Janeiro. Dissertação (Mestrado em Ensino em Biociências e Saúde) - Instituto Oswaldo Cruz, Rio de Janeiro, 2006.

BARDIN, L. Análise de conteúdo. Portugal: Edições 70,1979 .

BRAND, R. et al. Restoring Voluntary Control of Locomotion after Paralyzing Spinal Cord Injury, Science, v. 336, n. 6085, p. 1182-1185, jun. 2012.

FAHNESTOCK, J. Accommodating science: the rhetorical life of scientific facts. In: MCRAE, M.W.

(Ed.) The Literature of Science - perspectives on popular scientific writing, Georgia, The University of Georgia Press, 1993

KIERNAN, V. Embargoed Science. Urbana, IL: University of Illinois Press, 2006.

HOCHBERG, L. R. et al. Reach and grasp by people with tetraplegia using a neurally controlled robotic arm, Nature, v. 485, n. 7398, p. 372-375, maio 2012.

MASSARANI, L.; DAL COL, F; ALMEIDA C. A cobertura de ciência por jornais diários: em pauta a pesquisa nacional na Argentina, no Brasil e no México. Razón y Palabra, v. 13, n. 65, 2008. 
MASSARANI, L.; MOREIRA, I. A retórica e a ciência: dos artigos originais à divulgação científica. Ciência \& Ambiente, Santa Maria, v. 23, p. 31-48, 2002.

MASSARANI, L. et al. Science journalism in Latin America: A case study of seven newspapers in the region. JCOM. Journal of Science Communication, Trieste, v. 4, n. 3, p. 2, 2005.

MYLES, S. et al. Melanesian Blond Hair Is Caused by an Amino Acid Change in TYRP1, Science, v. 336, n. 6081, p. 554, maio 2012.

NELKIN, Dorothy. Selling Science. How the press covers science and technology. New York: W.H. Freeman and Company, 1995.

RENIE, J. Improving Science Journalism. 2011. Informações retiradas da fala de Jonh Renie durante a conferência Science On Line 2011. Disponível em: < http://blogs.plos.org/retort/2011/01/26/improvingscience-journalism/> . Acesso em: 05 abr. 2012.

SATURNO, W. et al. Ancient Maya Astronomical Tables from Xultun, Guatemala, Science, v. 336, n. 6082, p. 714-717, maio 212.

SCALLY, A. et al. Insights into hominid evolution from the gorilla genome sequence, Nature, v. 483, n. 7388, mar. 2012.

TRAQUINA, Nelson. Teorias do jornalismo: a tribo jornalística. Florianópolis: Insular/Pósjor UFSC, 2005. v. 2. $\mathrm{XU}, \mathrm{W}$. et al. A gigantic feathered dinosaur from the Lower Cretaceous of China, Nature, v. 484, n. 7392, abr. 2012. 
Embargoed Science: a case study of the newspapers 0 Globo and Folha

Ciencia embargada: un estudio de caso de los periódicos o Globo y Folha

\section{Resumen}

Este trabajo presenta un análisis de la influencia del sistema de embargo de las revistas científicas sobre la cobertura de ciência de los periódicos diarios brasileños $O$ Globo y Folha de S. Paulo. Este sistema permite que los periodistas reciban informaciones privilegiadas a cerca de artículos científicos aún no publicados con la expectativa de que tengan una mejor preparación de su cobertura. Realizamos un análisis cuantitativo y cualitativo de noticias producidas con base en el sistema de embargo de las revistas científicas Science y Nature publicadas en las secciones de ciencia de los periódicos $O$ Globo y Folha en un período de cinco meses del año 2012. En contraste con su objetivo declarado, nuestros resultados sugieren que este sistema no garantiza necesariamente una cobertura profundizada de la ciencia, sino una cobertura altamente influenciada por las publicaciones científicas, con tono consensual, sin la presencia de controversias, y con baja pluralidad de voces.

\section{Palabras clave}

Prensa diaria. Ciencia y médios de comunicación. Sistema de embargo. Divulgación de la ciencia 


\section{Expediente}

A revista E-Compós é a publicação científica em formato eletrônico da Associação Nacional dos Programas de Pós-Graduação em Comunicação (Compós). Lançada em 2004, tem como principal finalidade difundir a produção acadêmica de pesquisadores da área de Comunicação, inseridos em instituições do Brasil e do exterior.

\section{E-COMPÓS I www.e-compos.org.br I E-ISSN 1808-2599}

Revista da Associação Nacional dos Programas

de Pós-Graduação em Comunicacão.

Brasília, v.17, n.1, jan./abri. 2014.

A identificação das edições, a partir de 2008

passa a ser volume anual com três números.

\section{CONSELHO EDITORIAL}

Afonso Albuquerque, Universidade Federal Fluminense, Brasil Alberto Carlos Augusto Klein, Universidade Estadual de Londrina, Brasil Alex Fernando Teixeira Primo, Universidade Federal do Rio Grande do Sul, Brasil Ana Carolina Damboriarena Escosteguy, Pontifícia Universidade Católica do Rio Grande do Sul, Brasi

Ana Gruszynski, Universidade Federal do Rio Grande do Sul, Brasil Ana Silvia Lopes Davi Médola, Universidade Estadual Paulista, Brasil André Luiz Martins Lemos, Universidade Federal da Bahia, Brasi Ângela Freire Prysthon, Universidade Federal de Pernambuco, Brasil Antônio Fausto Neto, Universidade do Vale do Rio dos Sinos, Brasil Antonio Carlos Hohlfeldt, Pontifícia Universidade Católica do Rio Grande do Sul, Brasil Antonio Roberto Chiachiri Filho, Faculdade Cásper Líbero, Brasi Arlindo Ribeiro Machado, Universidade de São Paulo, Brasil Arthur Autran Franco de Sá Neto, Universidade Federal de São Carlos, Brasil Benjamim Picado, Universidade Federal Fluminense, Brasil César Geraldo Guimarães, Universidade Federal de Minas Gerais, Brasil Cristiane Freitas Gutfreind, Pontifícia Universidade Católica do Rio Grande do Sul, Brasil Denilson Lopes, Universidade Federal do Rio de Janeiro, Brasil Denize Correa Araujo, Universidade Tuiuti do Paraná, Brasi Edilson Cazeloto, Universidade Paulista , Brasil

Eduardo Vicente, Universidade de São Paulo, Brasil Eneus Trindade, Universidade de São Paulo, Brasil Erick Felinto de Oliveira, Universidade do Estado do Rio de Janeiro, Brasi Florence Dravet, Universidade Católica de Brasília, Brasil Gelson Santana, Universidade Anhembi/Morumbi, Brasi Gilson Vieira Monteiro, Universidade Federal do Amazonas, Brasil Gislene da Silva, Universidade Federal de Santa Catarina, Brasil Guillermo Orozco Gómez, Universidad de Guadalajara Gustavo Daudt Fischer, Universidade do Vale do Rio dos Sinos, Brasil Hector Ospina, Universidad de Manizales, Colômbia Herom Vargas, Universidade Municipal de São Caetano do Sul, Brasil Ieda Tucherman, Universidade Federal do Rio de Janeiro, Brasil Inês Vitorino, Universidade Federal do Ceará, Brasil Janice Caiafa, Universidade Federal do Rio de Janeiro, Brasil Jay David Bolter, Georgia Institute of Technology Jeder Silveira Janotti Junior, Universidade Federal de Pernambuco, Brasi João Freire Filho, Universidade Federal do Rio de Janeiro, Brasil John DH Downing, University of Texas at Austin, Estados Unidos
José Afonso da Silva Junior, Universidade Federal de Pernambuco, Brasil José Carlos Rodrigues, Pontifícia Universidade Católica do Rio de Janeiro, Brasil José Luiz Aidar Prado, Pontifícia Universidade Católica de São Paulo, Brasil José Luiz Warren Jardim Gomes Braga, Universidade do Vale do Rio dos Sinos, Brasil Juremir Machado da Silva, Pontifícia Universidade Católica do Rio Grande do Sul, Brasil Laan Mendes Barros, Universidade Metodista de São Paulo, Brasil Lance Strate, Fordham University, USA, Estados Unidos Lorraine Leu, University of Bristol, Grã-Bretanha Lucia Leão, Pontifícia Universidade Católica de São Paulo, Brasil Luciana Panke, Universidade Federal do Paraná, Brasil Luiz Claudio Martino, Universidade de Brasília, Brasil Malena Segura Contrera, Universidade Paulista, Brasil Márcio de Vasconcellos Serelle, Pontifícia Universidade Católica de Minas Gerais, Brasil Maria Aparecida Baccega, Universidade de São Paulo e Escola Superior de Propaganda e Marketing, Brasil Maria das Graças Pinto Coelho, Universidade Federal do Rio Grande do Norte, Brasil Maria Immacolata Vassallo de Lopes, Universidade de São Paulo, Brasil Maria Luiza Martins de Mendonça, Universidade Federal de Goiás, Brasil Mauro de Souza Ventura, Universidade Estadual Paulista, Brasil Mauro Pereira Porto, Tulane University, Estados Unidos Nilda Aparecida Jacks, Universidade Federal do Rio Grande do Sul, Brasil Paulo Roberto Gibaldi Vaz, Universidade Federal do Rio de Janeiro, Brasil Potiguara Mendes Silveira Jr, Universidade Federal de Juiz de Fora, Brasil Renato Cordeiro Gomes, Pontifícia Universidade Católica do Rio de Janeiro, Brasil Robert K Logan, University of Toronto, Canadá

Ronaldo George Helal, Universidade do Estado do Rio de Janeiro, Brasil Rosana de Lima Soares, Universidade de São Paulo, Brasil Rose Melo Rocha, Escola Superior de Propaganda e Marketing, Brasil Rossana Reguillo, Instituto de Estudos Superiores do Ocidente, Mexico Rousiley Celi Moreira Maia, Universidade Federal de Minas Gerais, Brasi Sebastião Carlos de Morais Squirra, Universidade Metodista de São Paulo, Brasil Sebastião Guilherme Albano da Costa, Universidade Federal do Rio Grande do Norte, Brasil

Simone Maria Andrade Pereira de Sá, Universidade Federal Fluminense, Brasil Tiago Quiroga Fausto Neto, Universidade de Brasilia, Brasil Suzete Venturelli, Universidade de Brasília, Brasil Valerio Fuenzalida Fernández, Puc-Chile, Chile Veneza Mayora Ronsini, Universidade Federal de Santa Maria, Brasil Vera Regina Veiga França, Universidade Federal de Minas Gerais, Brasil

\section{COMISSÃO EDITORIAL}

Cristiane Freitas Gutfreind I Pontifícia Universidade Católica do Rio Grande do Sul, Brasil Irene Machado I Universidade de São Paulo, Brasil

Jorge Cardoso Filho I Universidade Federal do Reconcavo da Bahia, Brasil / Universidade Federal da Bahia, Brasil

CONSULTORES AD HOC

Adriana Amaral, Universidade do Vale do Rio dos Sinos, Brasil

Alexandre Rocha da Silva, Universidade Federal do Rio Grande do Sul, Brasi Arthur Ituassu, Pontifícia Universidade Católica do Rio de Janeiro, Brasil Bruno Souza Leal, Universidade Federal de Minas Gerais, Brasil Elizabeth Bastos Duarte, Universidade Federal de Santa Maria, Brasil Francisco Paulo Jamil Marques, Universidade Federal do Ceará, Brasi Maurício Lissovsky, Universidade Federal do Rio de Janeiro, Brasil Suzana Kilpp, Universidade do Vale do Rio dos Sinos, Brasil Vander Casaqui, Escola Superior de Propaganda e Marketing, Brasil

EDIÇÃO DE TEXTO E RESUMOS I Susane Barros SECRETÁRIA EXECUTIVA I Helena Stigger EDITORAÇÃo ELETRÔNICA I Roka Estúdio
COMPÓS I www.compos.org.br

Associação Nacional dos Programas de Pós-Graduação em Comunicação

Presidente

Eduardo Morettin

Universidade de São Paulo, Brasil

eduardomorettin@usp.br

Vice-presidente

Inês Vitorino

Universidade Federal do Ceará, Brasil

ines@ufc.br

Secretária-Geral

Gislene da Silva

Universidade Federal de Santa Catarina, Brasil

gislenedasilva@gmail.com 